\title{
Hormone therapy and asymmetrical dimethylarginine in postmenopausal women
}

\author{
Artemis Karkanaki ${ }^{1}$, Dimitrios Vavilis ${ }^{2}$, Alexandros Traianos ${ }^{2}$, Ioannis Kalogiannidis ${ }^{1}$, \\ Dimitrios Panidis ${ }^{3}$
}

\begin{abstract}
${ }^{1} 4^{\text {th }}$ Department of Obstetrics and Gynecology, Aristoteles University of Thessaloniki, Ippokratio Hospital, ${ }^{2} 1^{\text {st }}$ Department of Obstetrics and Gynecology, Aristoteles University of Thessaloniki, Papageorgiou Hospital, ${ }^{3}$ Division of Endocrinology and Human Reproduction, $2^{\text {nd }}$ Department of Obstetrics and Gynecology, Aristoteles University of Thessaloniki, Ippokratio Hospital, Thessaloniki, Greece
\end{abstract}

\begin{abstract}
Women present an estradiol-dependent cardiovascular risk profile. Based on various studies, it was considered that estrogen therapy (ET) in postmenopausal women could probably reduce the higher cardiovascular risk in this group. Assymetric dimethylarginine (ADMA) is an endogenous methylated arginine which inhibits nitric oxide (NO) synthesis by competing with the substrate of NO, L-arginine, leading to endothelial dysfunction and, consequently, to atherosclerosis. Moreover, ADMA has been considered as an independent risk factor for cardiovascular disease. It has also been found that hormone therapy (HT), and mainly oral estrogen therapy, lowers ADMA concentrations in healthy postmenopausal women. The effect of estrogens on ADMA levels, although small, is considered important, as physiological variation of ADMA is limited. Nevertheless, larger randomized trials are necessary to establish that estrogens substantially lower ADMA levels and that these changes really reflect improved cardiovascular prognosis in postmenopausal women.
\end{abstract}

Key words: ADMA, Asymmetrical dimethylarginine, Estrogen therapy, Hormone therapy, HT, Menopause

\section{INTRODUCTION}

Estrogens have been known to exert various effects on the cardiovascular system., ${ }^{1,2}$ It has thus been shown that sex steroids retard the atherosclerotic process and induce rapid vasodilatation through the produc-

Address for correspondence:

Artemis Karkanaki, 30 Ioanninon Str., 54639 Thessaloniki, Tel.: 00306932315022, e-mail: kartemis2004@hotmail.com

Received 02-11-09, Revised 12-02-10, Accepted 05-03-10 tion of an endothelium-derived vasoactive mediator, nitric oxide (NO). ${ }^{2-4}$ Estrogen-induced vasodilatation via nitric oxide seems to be mediated by asymmetric dimethylarginine (ADMA) and ADMA serum concentrations are inversely related to endogenous estradiol levels. ${ }^{5}$

ADMA is an endogenous methylated arginine which inhibits NO synthesis, leading to endothelial dysfunction and consequent atherosclerosis. ${ }^{6}$ Experi- 
mental data have shown that ADMA is negatively correlated with flow-mediated vasodilatation ${ }^{7}$ and constitutes an important marker of carotid artery intima-media thickness. ${ }^{8}$ Even slightly increased ADMA blood levels are associated with higher risk for acute coronary events. ${ }^{9}$

Estradiol also exerts an anti-inflammatory effect in vitro, as well as in vivo, and accelerates endothelial regrowth, thus promoting vascular healing. ${ }^{10}$ Women present an age-dependent, and specifically an estradiol-dependent, cardiovascular disease risk pattern, ${ }^{11}$ as is demonstrated by the rise in the number of cardiovascular events after menopause.

Estrogen therapy (ET) has been considered as a means of reducing cardiovascular risk in postmenopausal women. ${ }^{12,13}$ Nevertheless, the validity of such intervention in cardiovascular disease (CVD) risk reduction remains controversial. ${ }^{14-16}$ It has been shown, however, that hormone therapy (HT) affects ADMA levels and other independent risk factors. ${ }^{17-20}$ Based on the observation that ADMA is linked to CVD, a review of available data on the impact of HT on ADMA and $\mathrm{CV}$ events was undertaken. ${ }^{21-25}$

\section{METHODS}

A comprehensive search was conducted via MEDLINE (http://www.ncbi. nlm.nih.gov/entrez/ medline.html) employing the keywords: asymmetric dimethylarginine, ADMA, estrogen replacement therapy, cardiovascular disease, and postmenopausal women. Our search included all possible combinations of keywords without any limitation in language or date. Fifty-six articles were found. Relevant citations in the reference lists of selected articles were also reviewed. Inclusion or exclusion of any article was based on relevance.

\section{MENOPAUSE}

Menopause is defined as the permanent cessation of menstruation following the loss of ovarian activity. Menopausal status is considered to begin at the cessation of menstruation ${ }^{26}$ and is characteristically accompanied by a 10-20-fold increase in FSH and a 3 -fold increase in $\mathrm{LH}$, with maximum values observed three years after menopause initiation. Following this stage, there is a gradual decline in both gonadotropins. However, estrogens still continue to circulate in postmenopausal women, these derived from the peripheral conversion of androgens ${ }^{27,28}$ that are still produced by the ovaries and the adrenal glands. ${ }^{29}$

\section{CARDIOVASCULAR RISK AND MENOPAUSE}

CVD represents the first cause of mortality and morbidity in both genders, with the onset established approximately ten years later in women than in men. ${ }^{30}$ Aging and estrogen deficiency have been reported as the most important factors of pertinent morbidity in women. ${ }^{31}$ The cessation of the ovarian function and the consequent reduction of sex steroid hormone levels have important metabolic and pathological consequences which adversely affect the cardiovascular system. Postmenopausal women have higher total cholesterol, LDL cholesterol, triglycerides, and a-lipoprotein levels and lower HDL cholesterol levels than premenopausal women. ${ }^{32,33}$ Transition to postmenopause is associated with augmentation in total and LDL-cholesterol values and a $16 \%$ increase in triglycerides, thus exceeding men's levels..$^{34,35}$ Finally, in the Study of Women's Health Across the Nation (SWAN), transition to menopause, and specifically falling estrogen levels, were associated with changes in the peripheral vasculature indicative of an increased risk for CVD in the postmenopausal period. ${ }^{36}$

\section{NON-GENOMIC ACTIONS OF ESTROGENS ON THE VASCULAR SYSTEM}

Human endothelial cell plasma membrane ${ }^{37}$ and vascular smooth muscle cells have estrogen receptors (ERs). ${ }^{38}$ Estrogens bind to these receptors and promote the activation of several kinase cascades, all of which have a common action, namely vasodilatation. ${ }^{1}$ Estradiol binds to ER $\alpha$ and activates the phosphatidylinositol 3-kinase (PI3K)/Akt pathway. Activated Akt catalyzes the phosphorylation of the endothelial isoform of nitric oxide synthase (eNOS), increasing its activity and leading to the increased production of NO. ${ }^{39} \mathrm{NO}$ is a potent vasodilator and mediates antiatherogenic and anti-inflammation actions. In the endothelial cells, the activation of PI3K/Akt modifies the expression of almost 250 genes, including cyclooxygenase, which mediates prostaglandin synthesis 
resulting in long-term changes in cellular function. ${ }^{40}$ Apart from this main pathway, there are several other actions on various pathways leading to rapid changes in calcium concentrations inside the endothelial cells and to induction of NO synthesis. ${ }^{41}$

Recent data have shown that estrogens also regulate cytoskeleton remodelling and endothelial cells migration to repair endothelial injuries..$^{42}$ Specifically, it has been found that non-transcriptional estrogen signals provoke instant re-arrangements of actin cytoskeleton and formation of membrane structures that promote movement to endothelial cells. Additionally, estrogens increase the permeability of junctions between endothelial cells and contribute to angiogenesis ${ }^{43}$ It must be stressed, however, that the function as well as the number of estrogen receptors decline with age. ${ }^{44}$

\section{HORMONE THERAPY AND CARDIOVASCULAR DISEASE}

Based upon the beneficial effects of the endogenous estrogens on the cardiovascular system and specifically on vasodilatation, it has been hypothesized that estrogen replacement therapy, alone or combined with progestins, might be capable of reducing the risk for cardiovascular disease in menopause. In fact, the positive effect of hormone therapy (HT) on endothelium-dependent vasodilatation was proven in healthy ${ }^{45,46}$ or low CVD risk ${ }^{47,48}$ postmenopausal women.

Publication of the estrogen-progestogen arm of the Women's Health Initiative (WHI) study in 2002 revealed that hormone therapy increased coronary heart disease, strokes, deep venous thrombosis, and breast cancer. ${ }^{49}$ Subsequent results of the WHI study reversed the negative attitude concerning HT by showing that there was no significant difference between combined estrogen progestin therapy and placebo use in the risk for CVD. ${ }^{50}$ Later, the ET arm of the WHI study also showed that there was no significant difference in cardiovascular events between the therapy and the placebo groups..$^{51}$ Both publications stated that there was no relation between the chronological and the menopausal age at therapy initiation and the observed effects. However, according to the final results of the ET arm of the study, there was a decrease in CVD risk when ET was initiated prior to the age of 60 years. ${ }^{52}$ Subsequent publications supported the age-related favourable effect of ET in CVD events. ${ }^{53,54}$ Currently, the use of HT is indicated as treatment of moderate to severe vasomotor symptoms. ${ }^{55-57}$ Still, it is not recommended for prevention of cardiovascular events at any age, even though short-term HT, administered to women of 50-59 years old, lowered the risk of CVD and all-cause mortality. ${ }^{58,59}$

\section{ASYMMETRIC DIMETHYLARGININE (ADMA)}

ADMA is an aminoacid produced by the degradation of methylated nuclear proteins. ADMA is produced in all tissues and is released in the plasma. It mainly acts as an endogenous inhibitor of all three isoforms of nitric oxide (NO) synthase ${ }^{60}$ and exerts important biological effects on the cardiovascular system. ADMA was first identified in 1992 and since then it has become the focus of great scientific interest. High serum levels of ADMA are found in pathological conditions leading to NO deficiency. Accumulation of ADMA results from increased methylation of proteins by methyltransferases (PRMT), precipitated proteolysis, decreased renal excretion, and impaired metabolism by N'G-dimethylarginine dimethylaminohydrolase (DDAH).

The amount of ADMA produced in cells depends on the rate of the protein metabolism and the methylation of arginine, since there is no known pathway of ADMA biosynthesis from free arginine. ${ }^{61}$ Its biosynthesis is mediated by PRMT. However, the exact mechanism regulating PRMT activity is unknown. Stress increases PRMT activity, and promotes ADMA synthesis in endothelial cells in vitro, through the activation of the transcription Nuclear Factor-B (NFB) ${ }^{62}$ Furthermore, low-density lipoproteins (LDL) stimulate PRMT activity and ADMA synthesis in the endothelium. ${ }^{63}$ Protein methylation is increased in proliferating cells. Additionally, anti-DNA antibodies in systemic lupus erythematosus promote methylation of ribonucleoproteins and may be responsible for the increased synthesis of methylarginine. ${ }^{64,65}$

Precipitated proteolysis may contribute to elevation of ADMA in hypercatabolic states such as endotoxemia, hyperthyroidism, and muscular dystrophy ${ }^{66-68}$ The intracellular metabolism of ADMA to 
L-citrulline and dimethylamine is mediated by the enzyme DDAH. ${ }^{69}$ About $10 \%$ of total ADMA enters the plasma and is excreted by the kidneys. Thus, any severe renal insufficiency is liable to lead to increased ADMA blood levels. ${ }^{70}$

Interestingly, ADMA molecules produced in the cells of a specific tissue may act and inhibit NO synthase in other tissues. Such a phenomenon is observed between macrophage and endothelial cells ${ }^{71}$ and possibly between smooth muscle and endothelial cells. It is speculated that this kind of action may comprise a trancellular signalling pathway. ${ }^{72}$ ADMA levels determine the rate of NO production with a relevant effect on blood vessels. ${ }^{73}$ It has been hypothesized that ADMA not only inhibits NO synthesis but its action as well. ${ }^{69}$ Inhibition of NO synthesis by an increase in ADMA levels also leads to disturbances in the vascular homeostasis models, namely dilatation versus constriction, activation of platelets, and unfavourable changes in transcellular communication. Altogether, the aforementioned modifications accelerate atherogenesis. ${ }^{74}$

\section{ADMA and cardiovascular disease}

There is ample evidence that ADMA, apart from producing effects related to NO synthase inhibition such as elevation of blood pressure, vasoconstriction, increased renovascular resistance, reduced forearm blood flow, reduced heart rate, and reduced cardiac output, also constitutes a marker of endothelial function and of cardiovascular risk. ${ }^{75-78}$ As already mentioned, ADMA levels are increased in various atherosclerotic conditions such as advanced age, hypertension, diabetes mellitus, hypercholesterolemia, and hyperhomocysteinemia. ${ }^{69}$ Moreover, ADMA concentrations are high both in asymptomatic subjects with hypercholesterolemia ${ }^{7}$ and in patients with cardiovascular or metabolic disease. ${ }^{79}$

Multivariate regression analyses of all known CDV risk factors showed that ADMA constitutes an independent risk factor for CDV. The practical value of such a marker becomes obvious in the group of patients of moderate risk, namely those who stand in the gray zone. ${ }^{78}$

It is relatively well established that ADMA not only reflects but also participates in the development of the atherosclerotic process. In a well designed prospective study, high ADMA levels were correlated with intima-media thickness (IMT), which is an independent prognostic factor of coronary disease. ${ }^{80} \mathrm{In}$ another study on the relation between cardiovascular risk and plasma ADMA concentrations in a cohort of haemodialysis patients followed for a mean period of 33.4 months, it was found that ADMA levels measured at start were correlated with the mortality observed throughout the study. ${ }^{81}$ In another study in patients with end-stage renal disease followed for a year, it was shown that ADMA was correlated and, moreover, represented a prognostic factor of IMT. ADMA levels and age were the most powerful prognostic markers of cardiovascular morbidity and mortality ${ }^{82}$ in this group.

Equally important was the study of patients hospitalized in an intensive care unit, in which it was shown that the mortality among patients with elevated ADMA concentrations was 17-fold higher, compared to the mortality of patients with lower values. ${ }^{81}$ In a prospective study of 153 patients with angina pectoris, subjected to selective coronary angioplasty and divided into groups according to the ADMA values prior to intervention and followed for an average period of 16 months, 51 cardiovascular events were noted. Coxs multivariate regression analysis revealed that the risk was positively correlated with ADMA incensement. Additionally, ADMA was an independent risk factor among age, smoking, hypercholesterolemia, and stent placing. ${ }^{82}$

It is worth mentioning that ADMA levels are higher in patients who manifest an acute coronary event compared to patients diagnosed with angina pectoris. ${ }^{83}$ There are many other prospective and well designed studies demonstrating the important role of ADMA as an independent prognostic marker of cardiovascular risk.

\section{ADMA and estrogens}

The favourable action of estrogens on the endothelium is mediated through stimulation of transcription of the endothelial isoform of the nitric oxide synthase (eNOs) gene ${ }^{41}$ and, furthermore, through the activation of the eNOs, during the binding with ERa, and through the PI3-kinase pathway. ${ }^{84}$ The end result of the estrogenic action (genomic and non genomic) is 
the maintenance of $\mathrm{NO}$ at normal or higher levels. Additionally, estrogens inhibit the accumulation of ADMA by increasing the activation (but not expression) of DDAH and by protecting the DDAH, which is sensitive to oxidative stress. ${ }^{25}$ Finally, estrogenic action per se is beneficial in the biochemical profile of classic $\mathrm{CV}$ risk factors.

The fact that ADMA levels are lower in premenopausal women than in men of the same age and rise in the postmenopausal period indicates an effect of estrogens in ADMA metabolism in vivo. ${ }^{85}$ Estrogens also inhibit the accumulation of ADMA in endothelial cells cultures, ${ }^{86}$ and in ovariectomised animals in vivo ${ }^{87}$ and can counteract the changes induced by oxLDL on the DDAH/ADMA/NO pathway. Specifically, estradiol counteracts oxidized LDL-induced ADMA production by cultured human endothelial cells. ${ }^{88}$

Furthermore, ADMA levels are significantly decreased a in hyperestrogenemic conditions such as pregnancy ${ }^{89}$ and ovulation induction with gonadotropins. ${ }^{86}$ By contrast, endothelial dysfunction in preeclampsia is characterised by high ADMA levels..$^{90,91}$ Finally, women with polycystic ovary syndrome present higher ADMA concentrations than controls, while treatment with combined estrogens and antiandrogens significantly decrease ADMA. ${ }^{92}$

\section{ADMA and hormone therapy}

ADMA having been established as an independent marker of endothelial function and cardiovascular risk is currently used in the assessment of the cardiovascular effects of hormone therapy. Following a two-week subcutaneous implantation of $100 \mathrm{mg}$ ethynylestradiol, Holden et al showed a significant reduction (around $18 \%$ ) of plasma ADMA concentration. ${ }^{25}$ In the same experiment, it was found that human and murine endothelial cell lines exposed to $17 \beta$-estradiol expressed a dose-dependent decrease, in ADMA production. ${ }^{25}$ This study supported retrospective and cross-sectional studies indicating that HT acts beneficially on the cardiovascular system. ${ }^{93}$

Teerlink et al demonstrated that conjugated estrogens, and raloxifene to a lesser extent, decrease ADMA levels in healthy postmenopausal women. ${ }^{21}$ The study included hysterectomized women who received either conjugated equine estrogens $(0.625 \mathrm{mg} / \mathrm{d})$, raloxifene or placebo. During the two-year treatment, there was a consistent reduction in ADMA levels only in women taking estrogens. The average post-baseline difference in ADMA was decreased by $8 \%(p=0.003)$. Interestingly, there was a trend towards a slight rise in ADMA concentrations in the placebo group throughout the two-year period, probably reflecting an effect of aging. Finally, reductions were also observed in the raloxifene group, although non-significant.

Research has also been focused on the type of estrogen therapy, the dose, the route of administration, and progestogens addition as to their effect on the cardiovascular system. Post et al conducted a study on 65 women who randomly received unopposed micronized $17 \beta$-estradiol $(2 \mathrm{mg} / \mathrm{d})$, or micronized $17 \beta$-estradiol $(2 \mathrm{mg} / \mathrm{d})$ plus either dydrogesterone $(10$ $\mathrm{mg} / \mathrm{d})$, or trimegestone $(0.5 \mathrm{mg} / \mathrm{d})$, or placebo during a 12-week period. ${ }^{22}$ The results showed reduction in ADMA levels in all treatment groups, but not in the placebo group. Compared to baseline and placebo, the greater reduction in ADMA concentration was noted in the estrogen plus trimegestone group (approximately 19\%) and less in the estrogen plus dydrogesterone group (almost $6.5 \%$ ), while in the unopposed estrogen group the reduction was $\approx 4 \%$. The same research team had shown $8 \%$ reduction with conjugated equine estrogens. ${ }^{21}$ The difference in ADMA changes between the dydrogesterone and trimegestone was attributed to the stronger antiestrogenic and antiandrogenic action of the latter.

In 2006, Verhoeven et al investigated the changes in ADMA levels according to the route of administration. ${ }^{23}$ The authors randomly assigned 152 women to receive either transdermal $17 \beta$-estradiol $(50 \mu \mathrm{g} / \mathrm{d})$, or oral micronized $17 \beta$-estradiol $(1 \mathrm{mg} / \mathrm{d})$ unopposed, or oral micronized $17 \beta$-estradiol $(1 \mathrm{mg} / \mathrm{d})$ plus gestodene $(25 \mu \mathrm{g} / \mathrm{d})$, for thirteen 28 -day cycles. They found significant reductions in all treatment groups. In fact, oral treatment groups presented greater reduction in ADMA levels than transdermal estrogen group. Compared to baseline, a $4.4 \%$ reduction was noted in the transdermal estrogen group $6.8 \%$ in the unopposed oral estrogen group and $8.5 \%$ in the oral estrogen plus gestodene group. The differences from baseline were similar to those found in two previous studies of the same research team. ${ }^{21,22}$ Gestodene in 
contrast to trimegestone seems to minimally influence the lowering effect of estrogens. The difference between the transdermal and oral administration may be attributed to the fact that ADMA is metabolized in the liver. ${ }^{94,95}$

Verhoeven et al randomly assigned 90 healthy postmenopausal women to receive either intranasal $17 \beta$-estradiol $(175 \mu \mathrm{g} / \mathrm{d})$ plus norethisterone $(275 \mu \mathrm{g} / \mathrm{d})$, or oral $17 \beta$-estradiol $(1 \mathrm{mg} / \mathrm{d})$ plus norethisterone $(0.5 \mathrm{mg} / \mathrm{d})$, for 52 weeks. ${ }^{24}$ They found that there was a significant reduction in ADMA levels only in the oral treatment group $(p<0.001)$. Specifically, the mean percentage decrease in ADMA levels, compared to baseline, was approximately $1.6 \%$ in the intranasal treatment group and $6.7 \%$ in the oral treatment group. It should be underlined that there was a consistent decrease of around $8 \%$ in ADMA concentrations by oral estrogens in the last and in the three previous studies, conducted by the same research team. The ADMA lowering effect is considered important, though statistically moderate, considering the fact that biological variation of ADMA in plasma concentration does not exceed $12 \% .{ }^{96}$

A recent study suggested that transdermal estrogen treatment had a modulating effect on ADMA plasma levels in patients who had undergone surgery in the early premenopausal period; ${ }^{97}$ after six months of treatment, women who received oral 17 $\beta$-estradiol did not present significant reduction in ADMA concentrations, while controls (no treatment) had significantly higher ADMA levels.

\section{CONCLUSIONS}

Hormone therapy has been traditionally prescribed for women complaining of climacteric symptoms rather than postmenopausal cardiovascular disease prevention. However, there has been growing interest in trying to additionally improve metabolic and cardiovascular risk in postmenopausal women through HT. Nevertheless, the report of the initial results of two large-scale randomized clinical trials, namely WHI and HERS, raised considerable scepticism and serious concerns regarding not only effectiveness but also adverse events of the hormonal therapy. Critical evaluation of these controversial results, in accordance with other observational and mostly cross-sectional studies, raised the question as to whether or not younger, early postmenopausal women with nonestablished vascular disease could be candidates for HT. For this reason, many cardiovascular risk markers are being sought and applied in pertinent studies in perimenopausal women.

ADMA, a NO synthase inhibitor, has proven to be an independent cardiovascular disease risk marker. Overall, HT, and particularly oral estrogen therapy, has been shown to lower ADMA concentrations, even within two weeks, in healthy postmenopausal women. The effect of estrogens on ADMA levels, although small, is considered important, as physiological variation is limited. Nevertheless, larger randomized trials are necessary to substantiate the notion that estrogens lower ADMA levels and that these changes really reflect improved cardiovascular prognosis in postmenopausal women.

\section{REFERENCES}

1. Simoncini T, Genazzani AR, 2003 Non-genomic actions of sex steroid hormones. Eur J Endocrinol 148: 281-292.

2. Mendelsohn ME, Karas RH, 1999 The protective effects of estrogen on the cardiovascular system. N Engl J Med 340: 1801-1811.

3. Adams MR, Kaplan JR, Manuc SB, et al, 1990 Inhibition of coronary artery atherosclerosis by 17-beta estradiol in ovariectomized monkeys. Lack of an effect of added progesterone. Arteriosclerosis 10: 1051-1057.

4. Gilligan DM, Quyyumi AA, Cannon RO III, 1994 Effects of physiological levels of estrogen on coronary vasomotor function in postmenopausal women. Circulation 89: 2545-2551.

5. Li XP, Zhou Y, Zhao SP, Cao M, Zhou QC, Li YS, 2004 Effect of endogenous estrogen on endothelial function in women with coronary heart disease and its mechanism. Clin Chim Acta 3339: 183-188.

6. Vallance P, Leone A, Calver A, Collier J, Moncada S, 1992 Accumulation of an endogenous inhibitor of NO synthesis in chronic renal failure. Lancet 339: 572575.

7. Böger RH, Bode-Böger SM, Szuba A, et al, 1998 Asymmetric dimethylarginine (ADMA): a novel risk factor for endothelial dysfunction: its role in hypercholesterolemia. Circulation 98: 1842-1847.

8. Miyazaki H, Matsuoka H, Cooke JP, et al, 1999 Endogenous nitric oxide synthase inhibitor: a novel marker of atherosclerosis. Circulation 99: 1141-1146.

9. Valkonen PV, Päivä H, Salonen JT, 2001 Risk of acute coronary events and serum concentration of asymmetrical 
dimethylarginine. Lancet 358: 2127-2128.

10. Arnal JF, Douin-Echinard V, Tremollières F, et al, 2007 Understanding the controversy about hormonal replacement therapy: insights from estrogen effects on experimental and clinical atherosclerosis. Arch Mal Coeur Vaiss 100: 554-562.

11. Bechlioulis A, Naka KK, Calis KA, et al, 2010 Cardiovascular Effects of Endogenous Estrogen and Hormone Therapy. Curr Vasc Pharmacol 8: 249-258.

12. Grodstein F, Stampfer MJ, Manson JE, et al, 1996 Postmenopausal estrogens and progestin use and the risk of cardiovascular disease. N Engl J Med 335: 453-461.

13. Barrett-Connor E, 1998 Fortnightly review: hormone therapy. BMJ 317: 457-461.

14. Manson JE, Hsia J, Johnson KC, et al, 2003 Estrogen plus progestin and the risk of coronary heart disease. N Engl J Med 349: 523-534.

15. Clarke SK, Kelleher J, Lloyd-Jones H, Slack M, Schofiel PM, 2002 A study of hormone therapy in postmenopausal women with ischemic heart disease: the Papaworth HT Atherosclerosis Study. Br J Obstet Gynecol 109: 10561062 .

16. Anderson GL, Limacher M, Assaf AR, et al, 2004 Effects of conjugated equine estrogen in postmenopausal women with hysterectomy: the Women's Health Initiative randomized controlled trial. J Am Med Assoc 291: 1701-1712.

17. Vogelvang TE, van der Moren MJ, Kamp O, Mijatovic V, Visser CA, Kenemans P, 2003 Effects of oral and transdermal low-dose estrogen therapy on echocardiographic paramenters of cardiac function. Fertil Steril 80: 546-553.

18. Post MS, van der Mooren MJ, van Baal WM, et al, 2003 Effects of low-dose oral and transdermal estrogen replacement therapy on hemostatic factors in healthy postmenopausal women: a randomized placebo-controlled study. Am J Obstet Gynecol 189: 1221-1227.

19. Hemelaar M, van der Mooren MJ, van Baal WM, Schalkwijk CG, Kenemans P, Stehouwer CD, 2005 Effects of transdermal and oral postmenopausal hormone therapy on vascular function: a randomized, placebo-controlled study in healthy postmenopausal women. Menopause 12: 526-535.

20. Post MS, Leurs JR, van der Mooren MJ, et al, 2005 Different effects of low-dose transdermal and oral oestrogen therapy on procarboxy-peptidase $U$, an inhibitor of fibrinolysis, in healthy postmenopausal women: a randomised, placebo-controlled study. Thromb Haemost 93: 620-622.

21. Teerlink T, Neele SJM, de Jong S, Netelenbos JC, Stehouwer CDA, 2003 Oestrogen replacement therapy lowers plasma levels of asymmetrical dimethylarginine in healthy postmenopausal women. Clin Sci 105: 6771.

22. Post MS, Marieke O, Verhoeven MJ, et al, 2003 Effect of hormone therapy on plasma levels of the cardiovascular risk factor asymmentric dimethylarginine: a randomized placebo-controlled 12-week study in healthy early postmenopausal women. J Clin Endocrinol Metab 88: 4221-4226.

23. Verhoeven MO, Hemelaar M, van der Mooren MJ, Kenemans P, Teerlink T, 2006 Oral, more than transdermal, oestrogen therapy lowers asymmentric dimethylarginine in healthy postmenopausal women: a randomized, placebo-controlled study. J Int Med 259: 199-208.

24. Verhoeven MO, Hemelaar M, Teerlink T, Kenemans P, van der Mooren MJ, 2007 Effects of intranasal versus oral hormone therapy on asymmetric dimethylarginine in healthy postmenopausal women: a randomized study. Atherosclerosis 195: 181-188.

25. Holden DP, Cartwright JE, Nussey SS, Whitley GS, 2003 Estrogen stimulates dimethylarginine dimethylaminohydrolase activity and the metabolism of asymmetric dimethylarginine. Circulation 108: 1575-1580.

26. Burger HG, Dudley EC, Robetson DM, Dennerstein L 2002 Hormonal changes in the menopause transition. Recent Prog Horm Res 57: 257-275.

27. Meldrum DR, Davidson BJ, Tataryn IV, Judd HL, 1981 Changes in circulating steroids with aging in postmenopausal women. Obstet Gynecol 57: 624-629.

28. Judd HL, Shamonki IM, Frumar AM, Lagasse LD, 1982 Origin of serum estradiol in postmenopausal women. Obstet Gynecol 59: 680-687.

29. Parker CR Jr, Slayden SM, Azziz R, et al, 2000 Effects of aging on adrenal function in the human: responsiveness and sensitivity of adrenal androgens and cortisol to adrenocorticotropin in premenopausal and postmenopausal women. J Clin Endocrinol Metab 85: 48-59.

30. American Heart Association 2001 Heart and stroke statistical update: American Heart Association. http://216.185.102.50/statistics/

31. Rossi R, Grimaldi T, Origliani G, Fantini G, Coppi F, Modena MG, 2002 Menopause and cardiovascular risk. Pathophysiol Haemost 32: 325-328.

32. Jensen J, Nilas L, Christiansen C, 1990 Influence of menopause on serum lipids and lipoproteins. Maturitas 12: 321-331.

33. Campos H, McNamara JR, Wilson PW, Ordovas JM, Schaefer EJ, 1988 Differences in low density lipoprotein subfractions and apolipoproteins in premenopausal and postmenopausal women. J Clin Endocrinol Metab 67: 30-35.

34. Poehlman ET, Toth MJ, Ades PA, Rosen CJ, 1997 Menopause-associated changes in plasma lipids, insulin-like growth factor I and blood pressure: a longitudinal study. Eur J Clin Invest 27: 322-326.

35. Razay G, Heaton KW, Bolton CH, 1992 Coronary heart disease risk factors in relation to the menopause. Q $\mathrm{J}$ Med 85: 889-896.

36. Wildman RP, Colvin AB, Powell LH, et al, 2008 Associations of endogenous sex hormones with the vasculature in menopausal women: the Study of Women's Health 
Across the Nation (SWAN). Menopause 15: 414-421.

37. Chambliss KL, Yuhanna IS, Mineo C et al, 2000 Estrogen receptor alpha and endothelial nitric oxide synthase are organized into a functional signalling module in caveolae. Circ Res 87: E44-E52.

38. Somjen D, Kohen F, Gayer B, et al, 2004 Role of putative membrane receptors in the effects of estradiol on human vascular cell growth. Am J Hypertens 17: 462-469.

39. Simoncini T, Rabkin E, Liao JK, 2003 Molecular basis of cell membrane estrogen receptor interaction with phosphatidylinositol 3-kinase in endothelial cells. Arterioscler Thromb Vasc Biol 23: 198-203.

40. Pedram A, Razandi M, Aitkenhead M, Hughes CCW, Levin ER, 2002 Integration of the non-genomic and genomic actions of estrogen. Membrane-initiated signalling by steroid to transcription and cell biology. J Biol Chem 277: 50768-50775.

41. Chambliss KL, Shaul PW, 2002 Estrogen modulation of endothelial nitric oxide synthase. Endocr Rev 23:665686.

42. Simoncini T, Scorticati C, Mannella P, et al, 2006 Estrogen receptor alpha interacts with Ga13 to drive actin remodelling and endothelial cell migration via the RhoA/Rhokinase/moesin pathway. Mol Endocrinol 20: 1756-1771.

43. Groten T, Pierce AA, Huen AC, Schnaper HW, 2005 17-beta estradiol transiently disrupts adherents junctions in endothelial cells. FASEB J 19: 1368-1370.

44. Losordo DW, Kearney M, Kim EA, Jekanowski J, Isner JM, 1994 Variable expression of the estrogen receptor in normal and atherosclerotic coronary arteries of premenopausal women. Circulation 89: 1501-1510.

45. Vehkavaara S, Hakala-Ala-Pietila T, Virkamaki A, et al, 2000 Differential effects of oral and transdermal estrogen replacement therapy on endothelial function in postmenopausal women. Circulation 102: 2687-2693.

46. de Kleijn MJ, Wilmink HW, Bots ML, et al, 2001 Hormone therapy and endothelial function. Results of a randomized controlled trial in healthy postmenopausal women. Atherosclerosis 159: 357-365.

47. Bush DE, Jones CE, Bass KM, Walters GK, Bruza JM, Ouyang P, 1998 Estrogen replacement reverses endothelial dysfunction in postmenopausal women. Am J Med 104: 552-528.

48. Gerhard M, Walsh BW, Tawakol A, et al, 1998 Estradiol therapy combined with progesterone and endotheliumdependent vasodilation in postmenopausal women. Circulation 98: 1158-1163.

49. Writing group for the Women's Health Initiative investigators, 2002 Risks and benefits of estrogen plus progestin in healthy postmenopausal women. JAMA 288: 2210-2232.

50. Manson JE, Hsia J, Johnson KC, et al, 2003 Estrogen plus progestin and the risk of coronary heart disease. N Engl J Med 349: 523-534.

51. The Women's Health Initiative Steering Committee, 2004 Effects of conjugated equine estrogen in postmenopausal women with hysterectomy. JAMA 291: 1701-1712.

52. Hsia J, Langer RD, Manson ME, et al, 2006 Conjugated equine estrogens and coronary heart disease. Arch Intern Med 166: 357-365.

53. Manson JE, Allison MA, Rossouw JE, et al, 2007 Estrogen therapy and coronary-artery calcification. N Eng J Med 365: 2591-2602.

54. Rossouw JE, Prentice RL, Manson JE, et al, 2007 Postmenopausal hormone therapy and risk of cardiovascular disease by age and years since menopause. JAMA 297: 1465-1477.

55. Pines A, Sturdee DW, Birkhaüser MH, et al, 2008 HT in the early menopause: scientific evidence and common perceptions. Climacteric 11: 267-272.

56. Rees M, Stevenson J, 2008 Primary prevention of coronary heart disease. Menopause Int 14: 40-45.

57. North Americn Menopause Society, 2008 Estrogen and progestogen use in postmenopausal women: July 2008 position statement of the North American Menopause Society. Menopause 13: 584-601.

58. Stevenson JC, 2009 Hormone therapy and cardiovascular disease revisited. Menopause Inter 15: 55-57.

59. Gass M, 2008 Highlights from the latest WHI publications and the latest North American Menopause Society position statement on use of menopausal hormone therapy. Clevel Clin J Med 75: Suppl 4: S13-16.

60. Vallance P, Leone A, Calver A, Collier J, Moncada S, 1992 Accumulation of an endogenous inhibitor of nitric oxide synthesis in chronic renal failure. Lancet 339: $572-5$.

61. Vallance P, Leiper J, 2004 Cardiovascular Biology of the Asymmetric Dimethylarginine: dimethylarginine Dimethylaminohydrolase Pathway. Arterioscler Thromb Vasc Biol 24: 1023-1030.

62. Osanai T, Saitoh M, Sasaki S, Tomita H, Matsunaga T, Okumura K, 2003 Effect of shear stress on asymmetric dimethylarginine release from vascular endothelial cells. Hypertens 42: 985-990.

63. Böger RH, Sydow K, Borlak J, et al, 2000 LDL cholesterol upregulates synthesis of asymmetrical dimethylarginine in human endothelial cells: involvement of S-adenosylmethionine-dependent methyltransferases. Circ Res 87: 99-105.

64. Bultink IE, Teerlink T, Heijst JA, Dijkmans BA, Voskuyl AE, 2005 Raised plasma levels of asymmetric dimethylarginine are associated with cardiovascular events, disease activity, and organ damage in patients with systemic lupus erythematosus. Ann Rheum Dis 64: 1362-1365.

65. Teerlink T, 2005 ADMA metabolism and clearance. Vasc Med 10: Suppl 1: S73-S81.

66. Hermenegildo C, Medina P, Peiro M, 2002 Plasma concentration of asymmetric dimethylarginine, an endogenous inhibitor of nitric oxide synthase, is elevated in hyperthyroid patients. J Clin Endocrinol Metab 87: 5636-5640.

67. Mittermayer F, Namiranian K, Pleiner J, Schaller G, 
Wolzt M, 2004 Acute Escherichia coli endotoxaemia decreases the plasma L-arginine/asymmetrical dimethylarginine ratio in humans. Clin Sci 106: 577-581.

68. Lou MF, 1979 Human muscular dystrophy: elevation of urinary dimethylarginines. Science 203: 668-670.

69. Cooke JP, 2005 ADMA: its role in vascular disease. Vasc Med 10: Suppl 1: S11-17.

70. Fleck C, Schweitzer F, Karge E, Busch M, Stein G, 2003 Serum concentrations of asymmetric (ADMA) and symmetric (SDMA) dimethylarginine in patients with chronic kidney diseases. Clin Chim Acta 336: 1-12.

71. Fickling SA, Holden DP, Cartwright JE, Nussey SS, Vallance P, Whitley G, 1999 Regulation of macrophage nitric oxide synthesis by endothelial cells: a role for NG, NG dimethylarginine. Acta Physiol Scand 167: 145-150.

72. Tran CT, Leiper JM, Vallance P, 2003 The DDAH/ ADMA/NOS pathway. Atheroscler Suppl 4: 33-40.

73. Vallance P, Leone A, Calver A, Collier J, Moncada S, 1992 Endogenous dimethyl-arginine as an inhibitor of nitric oxide synthesis. J Cardiovasc Pharmacol 20: Suppl 12: S60-S62.

74. Ross R, 1999 Atherosclerosis-an inflammatory disease. N Engl J Med 340: 115-126.

75. Cooke JP, 2004 Asymmetrical dimethylarginine: the Uber marker? Circulation 109: 1813-1818.

76. Cooke JP, 2000 Does ADMA cause endothelial dysfunction? Arterioscler Thromb Vasc Biol 20: 20-32.

77. Böger RH, 2006 Asymmetric dimethylarginine (ADMA): a novel risk marker in cardiovascular medicine and beyond. Ann Med 38: 126-136.

78. Miyazaki H, Matsuoka H, Cooke JP, et al, 1999 Endogenous nitric oxide synthase inhibitor: a novel marker of atherosclerosis. Circulation 99: 1141-1146.

79. Zoccali C, Bode-Böger S, Mallamaci F, et al, 2001 Plasma concentration of asymmetrical dimethylarginine and mortality in patients with end-stage renal disease: a prospective study. Lancet 358: 2113-2117.

80. Zoccali C, Benedetto FA, Maas R, et al, 2002 Asymmetric dimethylarginine, $\mathrm{C}$-reactive protein, and carotid intima-media thickness in end-stage renal disease. J Am Soc Nephrol 13: 490-466.

81. Nijveldt RJ, Teerlink T, Van Der Hoven B, et al, 2003 Asymmetrical dimethylarginine (ADMA) in critically ill patients: high plasma ADMA concentration is an independent risk factor of ICU mortality. Clin Nutr 22: 23-30.

82. Lu TM, Ding YA, Charng MJ, Lin SJ, 2003 Asymmetrical dimethylarginine: a novel risk factor for coronary artery disease. Clin Cardiol 26: 458-464.

83. Krempl TK, Maas R, Sydow K, Meinertz T, Böger RH, Kahler J, 2005 Elevation of asymmetric dimethylarginine in patients with unstable angina and recurrent cardiovascular events. Eur Heart J 26: 1846-1851.

84. Haynes MP, Sinha D, Russel KS, et al, 2000 Membrane estrogen receptor engagement activates eNOs via the PI-3-kinase/Akt pathway in human endothelial cells.
Circ Res 87: 677-682.

85. Schulze F, Maas R, Freese R, et al, 2005 Determination of a reference value for $\mathrm{NG}, \mathrm{NG}$-dimethyl-L-arginine in 500 subjects. Eur J Clin Invest 35: 622-626.

86. Cevik D, Unay O, Durmusoglu F, Yurdun T, Bilsel AS, 2006 Plasma markers of NO synthase activity in women after ovarian hyperstimulation: influence of estradiol on ADMA. Vasc Med 11: 7-12.

87. Ishibahshi T, Obayashi S, Sakamoto S, et al, 2006 Estrogen replacement effectively improves the accelerated intimal hyperplasia following balloon injury of carotid artery in the ovariectomized rats. J Cardiovasc Pharmacol 47: 37-45.

88. Monsalve E, Oviedo PJ, García-Pérez MA, Tarín JJ, Cano A, Hermenegildo C, 2007 Estradiol counteracts oxidized LDL-induced asymmetric dimethylarginine production by cultured human endothelial cells. Cardiovasc Res 73: 66-72.

89. Holden DP, Fickling S, Whitley G, Nussey S, 1998 Plasma concentration of asymmetric dimethylarginine, a natural inhibitor of nitric oxide synthase, in normal pregnancy and preeclampsia. Am J Obst Gynecol 178: 551-556.

90. Pettersson A, Hedner T, Milsom I, 1998 Increased circulating concentrations of asymmetric dimethylarginine (ADMA), an endogenous inhibitor of nitric oxide synthesis, in preeclampsia. Acta Obstet Gynecol Scand 77: 808-813.

91. Savvidou MD, Hingorani AD, Tsikas D, Frolich JC, Vallance P, Nicolaides KH, 2003 Endothelial dysfunction and raised plasma concentrations of asymmetric dimethylarginine in pregnant women who subsequently develop pre-eclampsia. Lancet 361: 1511-1517.

92. Charitidou C, Farmakiotis D, Zournatzi V, et al, 2008 The administration of estrogens, combined with anti-androgens, has beneficial effects on the hormonal features and asymmetric dimethyl-arginine levels, in women with the polycystic ovary syndrome. Atherosclerosis 196: 958-965.

93. Gray GA, Sharif I, Webb DJ, Seckl JR, 2001 Oestrogen and the cardiovascular system: the good, the bad and the puzzling. Trends Pharmacol Sci 22: 152-156.

94. Nijveldt RJ, Teerlink T, Siroen MPC, van Lambalgen AA, Rauwerda JA, van Leeuwen PAM, 2003 The liver is an important organ in the metabolism of asymmetrical dimethylarginine. Clin Nutr 22: 17-22.

95. Siroen MP, Warle MC, Teerlink T, et al, 2004 The transplanted liver graft is capable of clearing asymmetric dimethylarginine. Liver Transpl 10: 1524-1530.

96. Teerlink T, 2005 Measurement of asymmetric dimethylarginine in plasma: methodological considerations and clinical relevance. Clin Chem Lab Med 43: 11301138 .

97. Kilic S, Yilmaz N, Erdogan G, et al, 2009 Effect of nonoral estrogen on risk markers for metabolic syndrome in early surgically menopausal women. Climact 8: 1-8. 